Reviews

\title{
Business, Commerce, and Social Responsibility: Beyond Agenda. By Richard H. Reeves-Ellington and Adele Anderson. 1997. Lewiston, NY: Edwin Mellen Press. 260 pp.
}

\author{
Reviewed by Daniel P. Dolan, Assistant Professor, Center for Global \\ Communications, International University of Japan.
}

Corporate social responsibility (CSR) as both practice and theory spans a wide variety of issues, depending on what entities are perceived as being stakeholders. One organization may address CSR solely by providing day care facilities for working mothers, while the business down the street has an institutionalized CSR program designed to meet at least some of the most pressing business-related needs of shareholders, suppliers, customers, employees, the environment, and local community groups. Of particular contemporary interest are corporations whose global reach extends from well-heeled shareholders to local settlements in the Third World. Starbucks is expected by some to invest in social development where it buys its coffee. Nike is expected to transform local wage structures in the Indonesian factory towns where its running shoes are made.

If corporations do not assume these responsibilities on their own, governments are often expected to provide incentives for them to do so. An example of CSR on a potentially global scale is U.S. President Clinton's recently proposed $\$ 2$ billion in tax incentives over ten years to encourage private sector donation of computers, sponsorship of community technology centers, and technology training for workers. The goal of the initiative is to help close what has become known as the "digital divide" that apparently affords individuals and groups unequal access to new information technology and its benefits.

In Business, Commerce, and Social Responsibility, Reeves-Ellington and Anderson do not address the impacts of CSR on a range of specific stakeholders. Rather, the authors discuss CSR in the context of broad international impacts through application of what they call a "culturally interpretive approach" grounded in anthropology. They argue that productive social responsibility in commerce demands that organizational agendas typified by rules and legal principles give way to personal responsibility. The goal is to find the "fitting response" to business responsibility dilemmas through ongoing cultural learning and awareness of the many potential impacts of business decisions on a variety of stakeholders. Businesspersons should "co-create responsibility not by drowning out other sources of light with their own, but by reading wisely, adding their illumination to the wisdom of the community" (p. 237).

Consistent with their distrust of agendas, the authors do not attempt to promote any particular corporate social responsibility formula. They also counsel patience, pointing out in the preface that CSR is not likely to have much measurable impact on the short-term financial health of businesses. Lacking promises or situation-specific advice, this book is not even a distant cousin to popular attempts by business-related publications to list 101 ways to succeed in something. In fact, the intended audience is not businesspersons but rather graduate students or brave undergraduates in anthropology or business, although the authors add that "thoughtful business practitioners" might also want to take the plunge.

I found the book exhausting, often frustrating, but rewarding in places. Exhausting because 


\section{Reviews}

the first 65 pages slog along without a sense of focus or narrative momentum, the significance of ideas often lost in transit. Chapter summaries and a more attentive editor would have provided relief. Frustrating because the valuable insights provided in the preface and the final chapter could have been marshalled to steer the book in a direction more interesting to more readers. Rewarding because we are reminded clearly of what most of us understand at some level but what is too often obscured by stock market valuations and the thrill of mega-mergers: that business fundamentally is about people. The authors argue persistently that socially responsible business requires moral actors with freedom to tack with cultural sensitivity between the often- competing needs of the organization and its external environment. A fuller and more cogent exploration of this critical proposition, without much of the numbing theoretical discussion in the opening chapters, would make investment in the book less daunting (the only available printing is in hardback, selling for $\$ 89.95$ at two popular online bookstores).

In Chapters 1and 2 Reeves-Ellington and Anderson define terms, lay out theories and frameworks, and discuss the historical evolution of culture-based business ethics steeped in moral judgement to today's legalistic, rule-based conceptions. They describe social responsibility in business as "a commercial entity's integration within all the wider sociocultural contexts in which it operates" (p. 222). The authors also point out that culture is a "less-developed ethical terrain" for understanding corporate social responsibility than business ethics driven by agendas because of "the general absence of distinction between formal authority and informal culture as a web of meanings in live, daily interactions" (p. 16). Because recognition of this distinction demands considerable effort and time of organizations, formal policy directives prevail. The authors also develop an interesting "cultural learning model" in which understanding of particular value orientations is gained through attention to three primary aspects of social practice: artifacts, social knowledge, and cultural logic. They use Reeves-Ellington's personal experience with Japanese business encounters to provide examples.

Chapter 3 lends some much-needed vitality to the previous sections with a case study of the different leadership styles of Apple Computer's Steve Jobs and John Sculley. The authors claim that there are three kinds of leaders in organizations: managers, transactional leaders and transformational leaders. They also draw a useful distinction between business and commerce as potential engines of socially responsible practice. "Pure business" aims to maximize economic returns, whereas commercial organizations continuously reinterpret situations creatively to find the best fit between business needs and cultural demands. The thesis of the discussion is that managers and transactional leaders are effective at facilitating the financial motives of both pure business and commercial entities, but that transformational leaders act as shamans to "identify and develop a unifying whole with the external environment" (p. 88). The authors posit Sculley's role at Apple as transactional, in contrast to Jobs' shamanistic orientation, and they promote the importance of the latter for advancing social responsibility.

Many readers probably will find the extended treatment of shamanism tiresome and unnecessary. Consider the following excerpts: "While shamans have a keen awareness of differences and peculiarities (Krippner, 1988, p. 306), they alter the Cartesian paradigm of dichotomous thinking by drawing a sense of relatedness and continuums" (p. 85); "As mediators, shamans work between the spiritual and human worlds. They suspend normative rules of social order, and they screen their encounters with the omnipotent spiritual world" (p. 87); and "As a creative human being, the shaman experiences empathy with all sentience and thus can enter into the spirit of other sentient beings" (p. 88). I wonder if Jobs would be flattered or horrified by this description. Either way, the point that the authors hope to make is that visionary (shamanistic) leaders are critical for developing dynamic learning organizations capable of recognizing the importance of socially responsible commerce.

The Body Shop's explicit social responsibility agenda and the difficulties it has caused for the company is explored in Chapter 4. Reeves-Ellington and Anderson spend too many pages documenting and criticizing Body Shop's "lack of integrity" while adding little support to their central argument in this section. They propose that organizations that claim to be socially 
Reviews

responsible must not attempt to legislate responsibility via agenda, but instead must engage in sincere dialogue with cultural representatives to gain necessary social knowledge. The chapter is useful, however, as a way of contrasting agenda-driven social responsibility claims with more culturally interpretive strategies described in Chapters 5 and 6. Reeves-Ellington recounts his experiences as operations vice-president of a multinational pharmaceutical company he calls "Pharmco." His story in Chapter 6 describing his involvement in a problematic purchase of land in a Javanese farming community is both interesting and illustrative. Successful completion of the deal demanded accommodations to local circumstances and values that likely would send most companies looking elsewhere for a less complicated situation. Stylistically, it is a testament to the power of storytelling that this chapter is so much more engaging and satisfying than the first two.

The final chapter, "Beyond Agenda," is the richest and most informative section of the book. In fact, I recommend starting with the preface, skipping to Chapter 7, then returning to Chapter 1 and subsequent chapters. Here the authors provide a good summary of their argument, and offer a valuably reflexive set of alternative interpretations of central conclusions made regarding the Pharmco land purchase. This exercise is both courageous and an excellent example of the openness to competing explanations that is fundamental to their social responsibility thesis.

With increasing publications of books arguing for corporate social responsibility, I question the marketing strategy behind the design of this work. As textbook or graduate seminar reader the line of argument and learning objectives are too opaque. As popular business book, theoretical sections are unappealingly dense and singular focus on broad international implications of CSR is restrictive. A general business audience would ask for at least minimal discussion of CSR issues specifically related to human resources, investors, or financial incentives. This book falls uncomfortably between genre, but valuable observations are available to the adventurous.

\section{Which Home Do We Protect? The Challenge of Protecting Endangered Species and Property. A Review Essay on Private Property and the Endangered Species Act, edited by Jason F. Shogren. (1998). Austin: University of Texas Press. xv, 153 pp.}

\section{Reviewed by Richard Castelnuovo, College of Agricultural and Life Sciences, University of Wisconsin.}

As much as any part of our heritage, private property defines who we are as Americans. It is an organizing principle for our government and cultural symbol of our independence and freedom (Salamon, 1998: 175-6). Environmental laws challenge concepts of private property, imposing land use and other restrictions on private choice for the benefit of the public. No environmental law has had a more direct impact on private property than the Endangered Species Act (ESA). In turn, property rights have significantly influenced the course of the ESA and the fate of the species it protects. In the name of private property, individual landowners have raised the battle cry of "shoot, shovel and shut up" and destroyed species and critical habit to evade the law's reach (Van de Werf, 1995: B1). Using legitimate channels, they have mobilized to apply effective political pressure to change the law and its administration. Ultimately this controversy between the protection of property and the environment has transformed the ESA into one of the most 